\title{
Surface and basal boundary conditions at the Southern McMurdo and Ross Ice Shelves, Antarctica
}

\author{
C. GRIMA, ${ }^{1}$ I. $\mathrm{KOCH}^{2,3}$ J. S. GREENBAUM, ${ }^{1}$ K. M. SODERLUND, ${ }^{1}$ \\ D. D. BLANKENSHIP, ${ }^{1}$ D. A. YOUNG, ${ }^{1}$ D. M. SCHROEDER, ${ }^{4,5}$ S. FITZSIMONS $^{3}$ \\ ${ }^{1}$ Institute for Geophysics, University of Texas, Austin, TX 78758, USA \\ ${ }^{2}$ International Center for Integrated Mountain Development, Patan 44700, Nepal \\ ${ }^{3}$ Department of Geography, University of Otago, Dunedin 9016, New Zealand \\ ${ }^{4}$ Department of Geophysics, Stanford University, Stanford, CA 94305, USA \\ ${ }^{5}$ Department of Electrical Engineering, Stanford University, Stanford, CA, 94305, USA \\ Correspondence: C. Grima <cgrima@ig.utexas.edu>
}

\begin{abstract}
We derive the surface and basal radar reflectance and backscatter coefficients of the southern McMurdo Ice Shelf (SMIS) and part of the nearby Ross Ice Shelf (RIS), Antarctica, from radar statistical reconnaissance using a $60-\mathrm{MHZ}$ airborne survey. The surface coefficients are further inverted in terms of snow density and roughness, providing a spatial distribution of the processes contributing to the surface boundary conditions. We disentangle the basal coefficients from surface transmission losses, and we provide the basal coherent content, an indicator of the boundary geometric disorder that is also self-corrected from englacial attenuation. The basal radar properties exhibit sharp gradients along specific iso-depths, suggesting an abrupt modification of the ice composition and geometric structure. We interpret this behavior as locations where the pressure-melting point is reached, outlining fields of freezing and melting ice. Basal steps are observed at both SMIS and RIS, suggesting a common geometric expression of widespread basal processes. This technique offers a simultaneous view of both the surface and basal boundary conditions to help investigate the ice-shelf stability, while its application to airborne data significantly improves coverage of the difficult-to-observe ice-ocean boundary. It also provides constraints on thermohaline circulation in ice shelves cavities, which are analogs for icecovered ocean worlds.
\end{abstract}

Keywords: basal, ice shelf, processes, radar, roughness, surface

\section{INTRODUCTION}

Ice shelves control the drainage of grounded ice into the ocean fringing two-thirds of Antarctica (Bindschadler and others, 2011). Through lateral friction from the embayment sides or local pinning points that create a backstress (Matsuoka and others, 2015; Berger and others, 2016), they buttress glaciers and ice streams (Dupont and Alley, 2005; Gudmundsson, 2013). Upon their sudden disintegration, glaciers that originally fed the ice shelves have been observed to speed up (De Angelis and Skvarca, 2003; Scambos and others, 2004), accelerating the transfer of land ice into the ocean where it eventually melts and contributes sea level rise. It is thus important to understand what controls the stability of ice shelves.

Generally, thinning ice shelves are less stable than thickening ice shelves. A potentially long-lived ice-shelf accretes new mass not only through dynamic inflow from glaciers and ice streams but also through local accumulation of snow on the ice-shelf surface (Depoorter and others, 2013; Rignot and others, 2013a) and through basal freezing on (Fricker and others, 2001; Pritchard and others, 2012; McGrath and others, 2014; Moholdt and others, 2014) generating socalled marine ice (Tison and others, 1993). Ice shelves that accrete more basal ice than they lose ice due to melting have been called cold-cavity ice shelves (Rignot and others, 2013a). Warm-cavity ice shelves primarily melt at their base due to warm ocean currents (Rignot and others, 2013a), sometimes in distinct basal channels (Vaughan and others, 2012; Alley and others, 2016) that can be mirrored by surface melting (Dow and others, 2018), further thinning the ice-shelf and thus decreasing its stability. As a result of dynamic flow and heterogeneous stucture, ice shelves also develop brittle weaknesses, such as crevasses and rifts (Rack and Rott, 2004; De Rydt and others, 2018; King and others, 2018), resulting in ice mass loss through ice berg calving (Liu and others, 2015; Jansen and others, 2015), possibly as a result of hydrofracturing if combined with surface melting (Banwell and Macayeal, 2015). If more than just the passive shelf ice is removed, ice-shelf restraint is decreased (Fürst and others, 2016), also with the possibility of sudden ice-shelf disintegration (Scambos and others, 2003, 2009; Cook and Vaughan, 2010). When ice shelves are heterogeneous and composed partially of marine ice, the propagation of crevasses could be slowed (McGrath and others, 2014) due to the different temperature and material properties of marine ice (Dierckx and Tison, 2013).

Understanding the surface and basal boundary conditions of ice shelves can help in assessing ice-shelf mass balance and stability. Most previous studies use a combination of altimetry remote sensing products or airborne radar data to derive the ice-shelf surface elevation or meteoric ice thickness, respectively, and assume hydrostatic equilibrium to 
constrain the basal boundary of the ice-shelf (Fricker and others, 2001; Depoorter and others, 2013; Rignot and others, 2013a; Moholdt and others, 2014; Liu and others, 2015). Additionally, assumptions regarding firn extent and density have to be made (Ligtenberg and others, 2011). Very few studies have actually determined firn density using in situ methods (Medley and others, 2013; Kuipers Munneke and others, 2017), especially since the density can vary spatially and with depth due to refreezing of surface meltwater (Hubbard and others, 2016; Bevan and others, 2017). Constraining basal ice-shelf boundary conditions in situ is logistically even more challenging and only few studies have succeeded in excavating ice cores from the basal marine ice (Oerter and others, 1992; Tison and others, 1993; Treverrow and others, 2010) and rely mostly on a combination of ice penetrating radar data collected on the ground and GPS measurements (Jansen and others, 2013; McGrath and others, 2014). Smaller scale basal crevasses can also be detected this way (Arcone and others, 2016).

We use the radar statistical reconnaissance (RSR) technique (Grima and others, 2014b) applied to a 2014-15 very-high frequency (VHF) airborne radar survey acquired by the High Capability Radar Sounder 2 (HiCARS2) to assess the distribution of surface density and roughness of the southern McMurdo lce Shelf (SMIS) and part of the Ross Ice Shelf (RIS). Surface density derived from airborne data replaces in situ efforts of using firn cores in combination with surface height changes from automatic weather station data. It also extends the geographical coverage of accumulation rates derived from isochrone depths that are extracted from ground penetrating radar profiles (Medley and others, 2013). Surface roughness is relevant for more sophisticated ablation models using energy balance (van den Broeke and others, 2009) and helpful in detecting zones of large-scale roughness features such as surface melt ponds and former percolation areas (Banwell and Macayeal, 2015; Rutishauser and others, 2016; Bevan and others, 2017). We extend the application of RSR to the basal ice reflector of SMIS and RIS. The derived signal characters are related to the basal composition and geometric heterogeneities, both of which are indicators of basal mass balance controlled locally through melting and accumulation of frazil ice crystals during the formation of marine ice (i.e., accretion). This basal roughness has been suggested to be a crucial parameter in the redistribution of the melt/freeze pattern and the alteration of vertical circulation across the ice-shelf and, therefore, its long-term evolution and stability (Gwyther and others, 2015)

We first present the regional context related to the SMIS and RIS and describe the airborne radar data set used. Then, we introduce the RSR technique applied to the surface radar return and detail a new model for the inversion of the basal character from application of the RSR technique to the basal radar return. We present the results for both the surface and the base; subsequently using these characteristics to identify and classify basal units. Interpretations and hypotheses to account for the observed basal units and their radar properties are discussed in terms of basal melting and marine ice accretion and distribution.

\section{CONTEXT}

\subsection{Regional setting}

The SMIS is a small ice-shelf in Antarctica adjacent to, but separated from, the much larger RIS by a rift zone. SMIS has a heterogeneous ice composition and is made up of meteoric and marine ice, which is exposed at the surface in its south due to a negative surface ablation (Kellogg and others, 1991; Fitzsimons and others, 2012a; Koch and others, 2015). Since there is a large thickness difference to the adjacent RIS, a steep basal gradient to the much thinner SMIS likely facilitates generation of frazil ice crystals from buoyant supercooled melt water and thus the formation of basal marine ice (Koch, 2016). Due to its large surface gradients in local accumulation (Clifford, 2005; Koch, 2016), SMIS is believed to sustain itself.

The RIS is nourished by the inflow of prominent ice streams from the East and West Antarctic Ice Sheets (Rignot and others, 2011), but has shown little overall thickness changes in recent years (Pritchard and others, 2012). RIS is a cold-cavity ice-shelf (Rignot and others, 2013b), but experiences some basal melting to its west (Dinniman and others, 2007). A thin layer of marine ice has been detected at the base of the center of the ice-shelf (Zotikov and others, 1980), the small basal accumulation is likely ascribed to its shallow basal gradient (Depoorter and others, 2013) that does not promote fast supercooling of basal meltwater and thus the fast generation of frazil ice crystals (Martin, 1981; Daly, 1984) that agglomerate to form marine ice (Treverrow and others, 2010).

\subsection{Data}

HiCARS2 is a $60-\mathrm{MHz}$ central frequency $(f), 5-\mathrm{m}$ wavelength $(\lambda), 15-\mathrm{MHz}$ bandwidth $(B)$, airborne radar sounder maintained and operated by the University of Texas, Institute for Geophysics (UTIG) and flown on board a Basler BT-67. This radar system is similar to HiCARS (Peters, 2005) with upgraded components (Grima and others, 2016). The surface area illuminated by HiCARS2 is $200-400 \mathrm{~m}$ in diameter (pulse-limited footprint), growing with the aircraft range to the surface. Pulse compression by matched filtering provides a range (i.e., vertical) resolution $\delta v=c /(2 B \sqrt{\epsilon})$, where $C$ is the speed of light in vacuum and $\epsilon$ the dielectric constant (permittivity) of the sounded material, ranges from $\sim 5.6 \mathrm{~m}$ in pure ice $(\epsilon=3.15)$ to $\sim 9.5 \mathrm{~m}$ in dry-snow $(\epsilon=$ 1.1) (Kovacs and others, 1995).

The studied HiCARS2 data set was acquired during the 2014-15 austral summer and covers most of the SMIS extent and part of the RIS lying south of Minna Bluff (Fig. 1). Although the survey covers the northern McMurdo Ice Shelf (MIS), this region has not been studied since a brine layer in the firn prevents the detection of the ice/ocean interface at this wavelength and over a significant portion of the iceshelf (Grima and others, 2016). We have calibrated the signal from the surface return over the blue-ice outcrop in MIS depicted by Grima and others (2016) in their Figure 1, and assuming a permittivity of 3.15 for the surface.

The radar signal is reflected/scattered back to the antenna by every dielectric gradient on its propagation path until signal extinction. As the signal is transmitted at high repetition frequency along-track ( $2000 \mathrm{~Hz}$ for HiCARS2), a vertical cross-section is built providing subsurface dielectric horizons with a time-delay vertical axis. The surface-subsurface echo time-delay $(t)$ is related to depth $(h)$ through the velocity of light in the medium (c) by $t=2 h \sqrt{\epsilon} / c$. We have inverted $h$ for the first echo below the surface (when present) by considering $\epsilon=3.1$ (i.e., pure meteoric ice). The RSR technique, explained in more details in Section 3, 


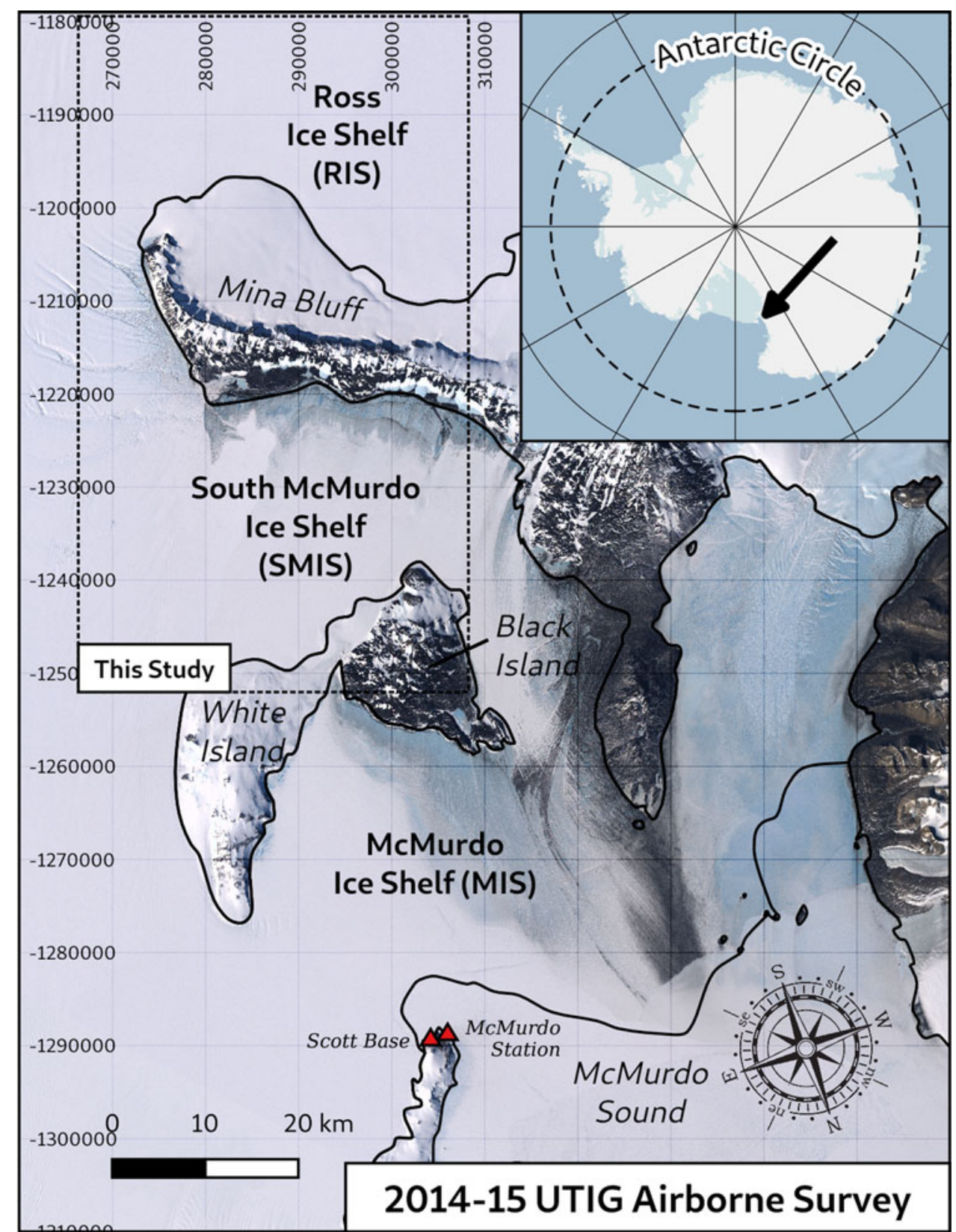

Fig. 1. Continental and regional maps illustrating the geographic context of the southern McMurdo Ice Shelf overlaid by the 2014-2015 UTIG airborne survey tracks (red lines). This study addresses the portion of the tracks covering SMIS and RIS. The background is the Landsat image mosaic of Antarctica (Bindschadler and others, 2008). All the maps in this manuscript use a standard universal polar stereographic (UPS) projection with a metric-based cartesian 'easting/northing' coordinate system.

is a radiometric approach essentially using the strength of a given echo as an observable.

\section{METHOD}

\subsection{Principles}

The energy radiated back to the antenna from a dielectric interface (e.g., air-ice or ice-ocean) is the coherent summation of all elementary electric fields reflected and scattered by the dielectric contrasts within a volume bounded horizontally by the circular radar footprint and vertically by the radar range resolution. Therefore, the echo strength holds crucial information about the composition and macro-structure $(>1 \%$ the wavelength in size) near the considered interface (Grima and others, 2014b). The RSR technique aims to provide two parameters to further characterize the echo strength and the properties of the related interface: (1) coherent energy reflected by the regularly distributed dielectric gradients, and (2) incoherent energy scattered by the random discontinuities of the medium. It can be shown analytically that the total energy received is the summation of both the coherent and incoherent ones (Ulaby and others, 1981).

The RSR technique has been applied to the surface echo over a wide range of planetary ice masses using airborne radar data: The Thwaites Glacier catchment and the northern MIS in Antarctica (Grima and others, 2014a,b, 2016) and the Devon Ice Cap in the Canadian Arctic (Rutishauser and others, 2016) for characterization of the firn density, surface roughness, near-surface brine, and refrozen ice from downward percolation. Using satellite radar data, the RSR surface technique has also successfully been applied 
on Mars for supporting the landing site selection of the NASA's InSight lander (Putzig and others, 2017) and to measure the waves riddling the hydrocarbon seas of Saturn's largest moon Titan (Grima and others, 2017).

Derivation of both coherent and incoherent energies are obtained by best-fitting the amplitude distribution of a set of surface echoes with a theoretical stochastic envelope whose parameters are a function of the coherent and incoherent energies (Destrempes and Cloutier, 2010). We use an envelope derived from Homodyne $K$-statistics (HK), a flexible model that does not require the condition of large scatterer numbers to be fulfilled and allows the scatterers to be clustered (non-stationarity) within the radar footprint (Jakeman, 1980; Jakeman and Tough, 1987). Here, we apply the RSR in the same manner as Grima and others (2016), i.e., the along-track data are divided into 1-km sampled spaces ( 1000 surface echoes each) repeated every $250 \mathrm{~m}$. A set of signal component pairs is then derived for every sampled space for both the surface echo and the first subsurface echo (when present) occurring after the surface return. In the following, the first subsurface return is called basal echo and is considered to be the base of the meteoric ice.

\subsection{Forward model}

Here we present a forward model to bound the received coherent-incoherent energy pairs to their respective coefficients describing the surface and basal reradiation properties. We consider a three-layer model where the horizontal medium 1 (ice) of thickness $h_{1}$ is sandwiched between the two half-spaces 0 (air) and 2 (ocean), respectively. The antenna lies in medium 0 and transmits down a coherent source of power $P_{0}$ at a distance $h_{0}$ from the surface bounded by 0 and 1 . The energy radiated back by the surface and the basal interface (bounded by 1 and 2) and intercepted by the antenna is $P_{\mathrm{s}}$ and $P_{\mathrm{b}}$, respectively, such as

$$
\begin{aligned}
& P_{\mathrm{s}}=\dot{P}_{\mathrm{s}}+\tilde{P}_{\mathrm{s}} \\
& P_{\mathrm{b}}=\dot{P}_{\mathrm{b}}+\tilde{P}_{\mathrm{b}}
\end{aligned}
$$

where the diacritic dot and tilde indicate the coherent and incoherent components of the signal, respectively. The link budget is the relationship between the energy transmitted by the source and the energy received at the antenna. It describes the propagation history of the signal and depends on the interface coefficients describing its capability to reradiate the energy of an impinging signal. For a rough surface in the normal direction, the interface coefficients are the effective reflectance $(\dot{R})$ and transmittance $(\dot{T})$ for the coherent part of the signal, as well as the backscatter $(\tilde{R})$ and forward-scatter $(\tilde{T})$ coefficients for the incoherent part. The expressions for both $\dot{P}_{\mathrm{s}}$ and $\tilde{P}_{\mathrm{s}}$ can be derived from their link budget, considering the surface as a specular reflector and as a scattering center, respectively:

$$
\begin{gathered}
\alpha \dot{P}_{\mathrm{s}}=L\left(2 h_{0}\right) \dot{R}_{\mathrm{s}} \\
\alpha \tilde{P}_{\mathrm{s}}=L\left(h_{0}\right)^{2} A_{\mathrm{s}} \tilde{R}_{\mathrm{s}}
\end{gathered}
$$

where $\alpha$ is a calibration factor in square meters accounting for the instrumental gains and including the antenna aperture. $L$ $(z)=1 /\left(4 \pi z^{2}\right)$ are the losses from isotropic geometric spreading along a distance $z$, and $A_{\mathrm{s}}$ is the footprint area at the surface. Likewise, the link budget for $\dot{P}_{\mathrm{b}}$ and $\tilde{P}_{\mathrm{b}}$ can be obtained from their propagation history illustrated by Figure 2 . At each interface, the impinging signal is broken out into a coherent and incoherent signal modulated by the interface coefficients, and so on, so that $P_{\mathrm{b}}$ is the sum of eight contributions, $P_{\mathrm{b}_{1}}$ to

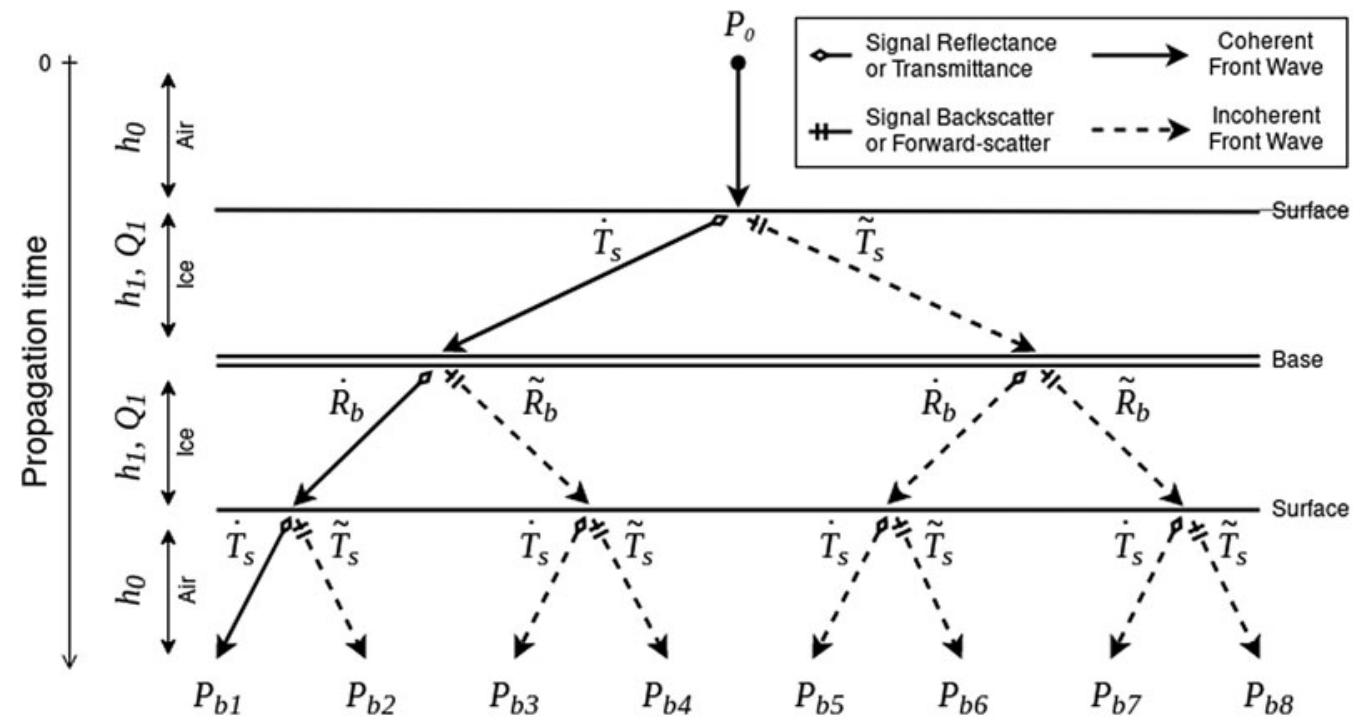

Fig. 2. Illustration of the propagation history of the basal signal from emission $\left(P_{0}\right)$ to reception $\left(\sum_{k=1}^{8} P_{\mathrm{b}_{k}}\right)$ at the antenna. Chronologically, the signal is first transmitted through the surface, radiated back from the base, then transmitted a second time through the surface. At each interaction with an interface the signal is split into a coherent and incoherent part and so on. Each part is determined by a reflectance/ transmittance or backscatter/forward-scatter coefficient, respectively. A backscatter/forward-scatter coefficient along a propagation history indicates a scattering center. A scattering center transforms an incoming coherent front wave into a incoherent front wave. A new geometric losses factor $(L(z))$ must be applied after each scattering center to account for signal diffusion. 
$\sum_{k=1}^{8} P_{\mathrm{b}^{\prime}}$, each with their own propagation history.

$$
\begin{aligned}
& \alpha P_{\mathrm{b}_{1}}=Q_{1}^{2} L\left(2 h_{0}+2 h_{1}\right) \dot{T}_{\mathrm{s}}^{2} \dot{R}_{\mathrm{b}} \\
& \alpha P_{\mathrm{b}_{2}}=Q_{1}^{2} L\left(h_{0}+2 h_{1}\right) L\left(h_{0}\right) \dot{T}_{\mathrm{s}} \dot{R}_{\mathrm{b}} A_{\mathrm{s}} \tilde{T}_{\mathrm{s}} \\
& \alpha P_{\mathrm{b}_{3}}=Q_{1}^{2} L\left(h_{0}+h_{1}\right) L\left(h_{0}+h_{1}\right) \dot{T}_{\mathrm{s}}^{2} A_{\mathrm{b}} \tilde{R}_{\mathrm{b}} \\
& \alpha P_{\mathrm{b}_{4}}=Q_{1}^{2} L\left(h_{0}+h_{1}\right) L\left(h_{1}\right) L\left(h_{0}\right) \dot{T}_{\mathrm{s}} A_{\mathrm{b}} \tilde{R}_{\mathrm{b}} A_{\mathrm{s}} \tilde{T}_{\mathrm{s}} \\
& \alpha P_{\mathrm{b}_{5}}=Q_{1}^{2} L\left(h_{0}\right) L\left(2 h_{1}+h_{0}\right) A_{\mathrm{s}} \tilde{T}_{\mathrm{s}} \dot{R}_{\mathrm{b}} \dot{T}_{\mathrm{s}} \\
& \alpha P_{\mathrm{b}_{6}}=Q_{1}^{2} L\left(h_{0}\right) L\left(2 h_{1}\right) L\left(h_{0}\right) A_{\mathrm{s}}^{2} \tilde{T}_{\mathrm{s}}^{2} \dot{R}_{\mathrm{b}} \\
& \alpha P_{\mathrm{b}_{7}}=Q_{1}^{2} L\left(h_{0}\right) L\left(h_{1}\right) L\left(h_{0}+h_{1}\right) A_{\mathrm{s}} \tilde{T}_{\mathrm{s}} A_{\mathrm{b}} \tilde{R}_{\mathrm{b}} \dot{T}_{\mathrm{s}} \\
& \alpha P_{\mathrm{b}_{8}}=Q_{1}^{2} L\left(h_{0}\right) L\left(h_{1}\right) L\left(h_{0}\right) L\left(h_{1}\right) A_{\mathrm{s}}^{2} \tilde{T}_{\mathrm{s}}^{2} A_{\mathrm{b}} \tilde{R}_{\mathrm{b}}
\end{aligned}
$$

where $Q_{1}$ is the one-way attenuation in medium 1 , the $s$ and $b$ subscripts denote the surface and basal coefficients, respectively, while $A_{\mathrm{b}}$ is the pulse-limited footprint area at the basal interface. Of interest, we note symmetries in propagation histories so that $P_{\mathrm{b}_{2}}=P_{\mathrm{b}_{5}}$ and $P_{\mathrm{b}_{4}}=P_{\mathrm{b}_{7}}$. Among those contributions, only $P_{\mathrm{b}_{1}}$ keeps a coherent character since it is not affected by a scattering coefficient. Hence, the coherent and incoherent powers detected at the antenna can be written as

$$
\begin{gathered}
\dot{P_{\mathrm{b}}}=P_{\mathrm{b}_{1}} \\
\tilde{P}_{\mathrm{b}}=\sum_{k=2}^{8} P_{\mathrm{b}_{k}}
\end{gathered}
$$

It is worth noting that the above model allows a portion of the incoming coherent energy to be transferred into incoherent energy at each reflection/transmission. Conversely, it does not allow for any incoming incoherent energy to be transferred into a coherent one, thus neglecting the peculiar effect of coherent scattering (Akkermans and others, 1986) that we assume to be non-effective in the terrestrial cryosphere at the considered wavelength $(5 \mathrm{~m})$.

\subsection{Coefficients inversion}

The surface interface reflectance and backscatter coefficients can easily be obtained from inversion of Eqn 2:

$$
\begin{gathered}
\dot{R}_{\mathrm{s}}=\frac{\alpha \dot{P}_{\mathrm{s}}}{L\left(2 h_{0}\right)} \\
\tilde{R}_{\mathrm{s}}=\frac{\alpha \tilde{P}_{\mathrm{s}}}{A_{\mathrm{s}} L\left(h_{0}\right)^{2}}
\end{gathered}
$$

$\tilde{R}_{\mathrm{S}}$ is usually associated with the normalized Radar Cross Section (aka nRCS, or $\sigma^{\circ}$ ) of the surface by radar scatterometers (e.g., Synthetic Aperture Radar imagery). However, in contrast to radar sounders, monostatic scatterometers usually measure the backscattered energy in the off-nadir directions and are then insensitive to the coherent energy determined by $\dot{R}_{\mathrm{s}}$ that propagates around the specular direction only.

Likewise, the basal reflectance and backscatter coefficients can be obtained after algebraic manipulation of Eqn 4:

$$
\dot{R}_{\mathrm{b}}=\frac{\alpha \dot{P_{\mathrm{b}}}}{\beta_{1} Q_{1}^{2}}
$$

$$
\tilde{R}_{\mathrm{b}}=\frac{\alpha \tilde{P}_{\mathrm{b}} / Q_{1}^{2}-\dot{R}_{\mathrm{b}}\left(\beta_{2}+\beta_{5}+\beta_{6}\right)}{\left(\beta_{3}+\beta_{4}+\beta_{7}+\beta_{8}\right)}
$$

with

$$
\begin{aligned}
& \beta_{1}=L\left(2 h_{0}+2 h_{1}\right) \dot{T}_{\mathrm{s}}^{2} \\
& \beta_{2}=L\left(h_{0}+2 h_{1}\right) L\left(h_{0}\right) \dot{T}_{\mathrm{s}} \tilde{T}_{\mathrm{s}} A_{\mathrm{s}} \\
& \beta_{3}=L\left(h_{0}+h_{1}\right) L\left(h_{0}+h_{1}\right) \dot{T}_{\mathrm{s}}^{2} A_{\mathrm{b}} \\
& \beta_{4}=L\left(h_{0}+h_{1}\right) L\left(h_{1}\right) L\left(h_{0}\right) \dot{T}_{\mathrm{s}} \tilde{T}_{\mathrm{s}} A_{\mathrm{s}} A_{\mathrm{b}} \\
& \beta_{5}=\beta_{2} \\
& \beta_{6}=L\left(h_{0}\right) L\left(2 h_{1}\right) L\left(h_{0}\right) \tilde{T}_{\mathrm{s}}^{2} A_{\mathrm{s}}^{2} \\
& \beta_{7}=\beta_{4} \\
& \beta_{8}=L\left(h_{0}\right) I\left(h_{1}\right) L\left(h_{0}\right) L\left(h_{1}\right) \tilde{T}_{\mathrm{s}}^{2} A_{\mathrm{s}}^{2} A_{\mathrm{b}}
\end{aligned}
$$

Note that the basal coefficients include correction from surface transmission and scattering (including roughness). The parameters in Eqn 6 and Eqn 7 are known or can be assessed following the methodology described thereafter. $\alpha$ is intrinsic to the knowledge of the instrumental gain and signal stability. Ultimately, it can be obtained from absolute calibration over a known terrain (Grima and others, 2014a, 2016). The surface and basal pulse-limited footprint area are (Peters, 2005):

$$
\begin{gathered}
A_{\mathrm{s}}=\frac{\pi \mathrm{c} h_{0}}{B_{\mathrm{w}}} \\
A_{\mathrm{b}}=\frac{\pi c\left(h_{0}+h_{1} / n_{1}\right)}{B_{\mathrm{w}}}
\end{gathered}
$$

where $c$ is the speed of light in vacuum, $B_{\mathrm{w}}$ is the radar bandwidth, and $n_{1}=\sqrt{\epsilon_{1}}$ is the refractive index of the ice. The surface transmission coefficients, $\dot{T}_{\mathrm{s}}$, and $\tilde{T}_{\mathrm{s}}$, are functions of the surface coefficients derived by Eqn 5, the refractive index of the ice, and the surface root-mean-square height $\left(\sigma_{h_{1}}\right)$ (Ulaby and others, 1981):

$$
\begin{gathered}
\dot{T}_{\mathrm{s}}=\left|\frac{4 n_{1}}{\left(1+n_{1}\right)^{2}}\right| \mathrm{e}^{-k^{2} \sigma_{h_{1}}^{2}\left(1-n_{1}\right)^{2}} \\
\tilde{T}_{\mathrm{s}}=n_{1} \tilde{R}_{\mathrm{s}}
\end{gathered}
$$

where $k=2 \pi / \lambda$ is the wave number. Assessments for the englacial attenuation $Q_{1}$, the surface properties $\epsilon_{1}$, and $\sigma_{\mathrm{h}_{1}}$, are discussed in Section 3.4, the last two being directly estimated from the surface coefficients previously derived from Eqn 5.

\subsection{Physical properties inversion}

$\dot{R}_{\mathrm{s}}, \tilde{R}_{\mathrm{s}}, \dot{R}_{\mathrm{b}}$, and $\tilde{R}_{\mathrm{b}}$ are modulated by physical properties of the target such as the interface dielectric gradient and their geometric heterogeneity. These properties can be inverted from the coefficients through a backscattering model. We used the methodology demonstrated by Grima et al. (2014a; 2016) to derive $\epsilon_{1}$ and $\sigma_{\mathrm{h}_{1}}$. This approach uses the Small Perturbation Model with the assumption of large correlation length (>100 m) (Grima and others, 2014b). Note that this model is expected to fail when $\sigma_{\mathrm{h}_{1}}$ is greater than $5 \%$ of 
the wavelength $(\lambda=5 \mathrm{~m})$, i.e., $0.25 \mathrm{~m}$. The derived surface permittivity $\epsilon_{1}$ can then be directly translated into dry-firn density (Kovacs and others, 1995).

Quantitative inversion of basal physical properties is more challenging due to additional unknowns. First, one needs to define an englacial attenuation factor. We chose a homogeneous attenuation of $Q_{1}=11 \mathrm{~dB} \cdot \mathrm{km}^{-1}$, a value reported as a peak occurrence for Antarctic ice shelves (Matsuoka and others, 2012). However, attenuation within marine ice can be significantly higher (Pettinelli and others, 2015); we would then underestimate the englacial attenuation where accreted marine ice is thick. The covered region has too little thickness change to estimate the attenuation empirically following Schroeder and others (2016). To by-pass this issue, it is elegant to refer to $\dot{R}_{\mathrm{b}} / \tilde{R}_{\mathrm{b}}$, or the coherent content of the interface coefficients. This name refers to, but is different from, the specular content, which is a ratio of nadir versus off-nadir energy that can be assessed after azimuthal processing of the signal (Schroeder and others, 2013, 2015). Because it is a ratio of two values derived from signals with the same propagation path, the coherent content cancels the effect of englacial attenuation. It is also independent of the dielectric contrast at the interface (Grima and others, 2012, 2014b). Thus, the coherent content is a measurement inversely correlated to the occurrence of geometric heterogeneities and their relative magnitude (i.e., dimension) within the radar vertical resolution near the interface (about $5 \mathrm{~m}$ in ice and $1 \mathrm{~m}$ in water). Importantly, the interface roughness is not the only dominant geometric heterogeneity that could produce signal scattering at the base. For instance, the presence of brine pockets or frazil ice at the ice/ocean interface are a subset of different settings that could produce dielectric heterogeneities that may be large enough to contribute to the radar backscatter (Kendrick and others, 2018). Then, if one cannot unambiguously invert a basal roughness as done for the surface, the coherent content is a reliable proxy for mapping the location of such scattering sources.

\section{SURFACE PROPERTIES}

The derivation of the surface RMS height and firn density as described in Section 3.4 is shown over SMIS and RIS in Fig. 3.

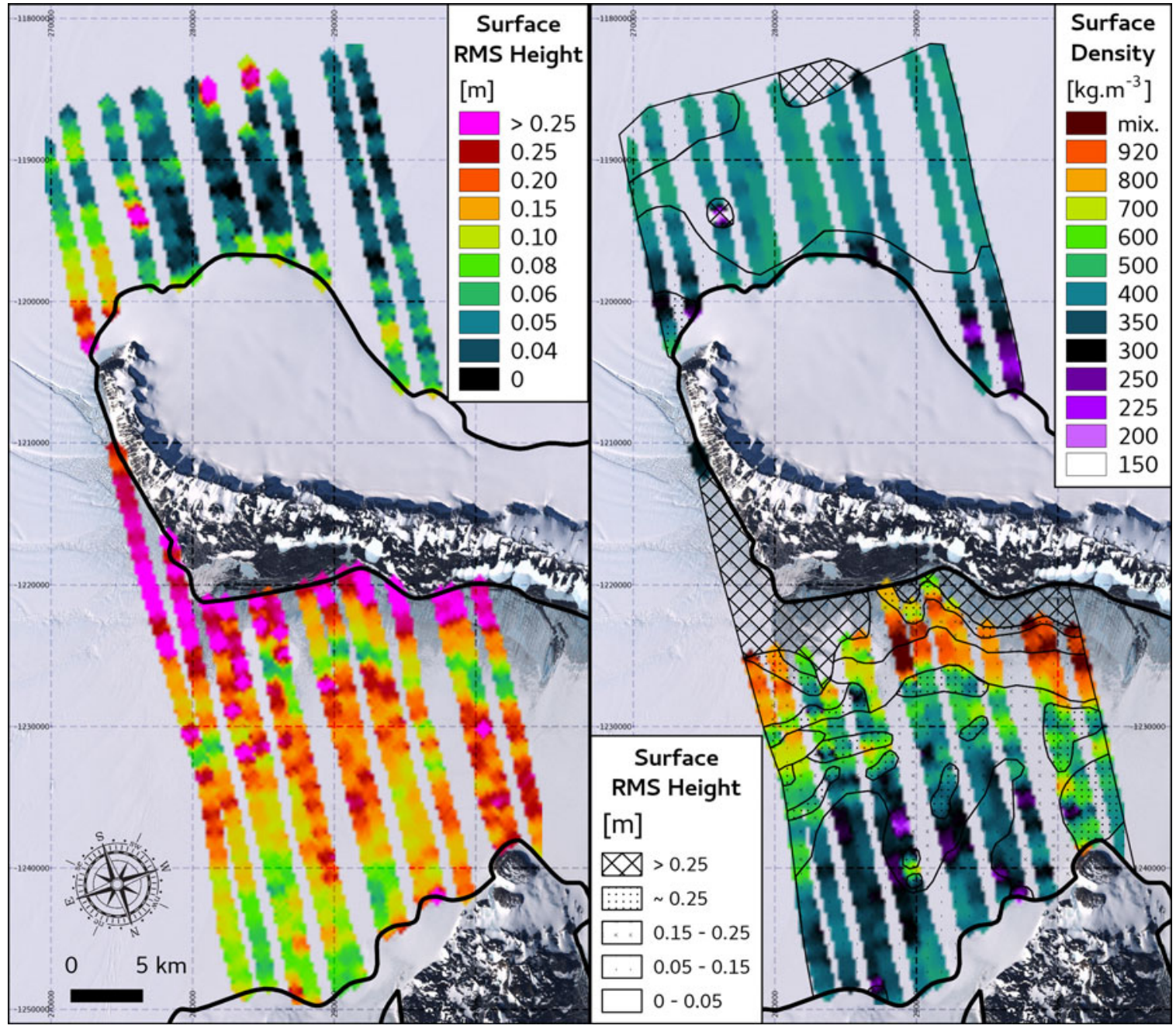

Fig. 3. (Left) Derived surface root-mean-square (RMS) height. Values $>0.25 \mathrm{~m}$ are beyond the application limits of the backscattering model and are considered underestimated. (Right) Surface density derived where the RMS height is $<0.25 \mathrm{~m}$, as allowed by the model's application limits (Grima and others, 2014b). The map is superimposed with a classification of the derived surface RMS height for comparison. As for subsequent maps, the background is the Landsat image mosaic of Antarctica (Bindschadler and others, 2008) that is superimposed by a 10-km-spaced grid matching the grid on Figure 1 to recover absolute coordinates. 


\subsection{Surface roughness}

Overall, the surface RMS height (Fig. 3. left) appears smoother and more homogeneous over the surveyed portion of RIS, with most values $<0.08 \mathrm{~m}$, than the SMIS where the roughness range is mostly $>0.08 \mathrm{~m}$ and exhibits a more specific pattern. The SMIS surface is rough along the southern edge of Minna Bluff, characterized by elongated ridges several meters in height that run perpendicular to the bluff (Koch and others, 2015; Koch, 2016). This area is also distinguishable as a blue ice area in the Landsat Image (Fig. 1) and coincides with the area where RMS height is $>0.25 \mathrm{~m}$. Further to the center of SMIS, the roughness decreases to $0.20 \mathrm{~m}$ in line with observations of sastrugi on the ice-shelf surface (Clifford, 2005) and eventually to $0.08 \mathrm{~m}$ in the vicinity of White Island. This evolution is not continuous though; at the southern edge of the blue ice area there is a narrow band, about $2 \mathrm{~km}$ in width, with a low apparent roughness down to $0.06 \mathrm{~m}$. This area coincides with a change from marine ice exposed at the surface of southern SMIS to meteoric ice (Koch, 2016), which is not as dark as the marine ice and thus likely has a higher surface albedo, encouraging less melt in comparison and therefore smoother terrain. Additionally, the occasional seasonal snow cover here is thin enough to hinder sastrugi formation.

\subsection{Surface density}

The snow and firn density of ice masses at their surface is dependent on overburden pressure, air temperature, relative humidity, and wind redistribution (Kaspers and others, 2004; Ligtenberg and others, 2011; Grima and others, 2014a). The radar-derived density pattern of this study (Fig. 3. right) shows that light snow $\left(<400 \mathrm{~kg} \cdot \mathrm{m}^{-3}\right)$ is gathered in the north and toward the center of SMIS. This matches the density observations from the upper meters of a firn core extracted from northern SMIS (Rosier and others, 2017). SMIS surface density is increasing southward toward Minna Bluff, finally reaching that of compact ice $\left(920 \mathrm{~kg} \cdot \mathrm{m}^{-3}\right)$ in its blue ice area where the ice-shelf surface mass balance is negative (Koch, 2016), allowing basal marine ice layers to crop out as evident by the ice's composition (Kellogg and others, 1991; Fitzsimons and others, 2012a; Koch and others, 2015). The presence of sastrugi in the ice-shelf center (Clifford, 2005) is evidence of high wind velocities, coinciding with firn densities of $400-700 \mathrm{~kg} \cdot \mathrm{m}^{-3}$ that likely arise from the windpacking.

\subsection{Marine-to-meteoric ice transition}

The smooth band along the marine ice exposure has a similar density, although appearing with an albedo that is indiscernible from the snow-covered part of the ice-shelf on satellite imagery. We interpret this band as marine ice covered by a thin veneer of possibly seasonal and/or wind-blown snow, which is supported by in field ground-based radar and ice sample evidence (Koch, 2016). It can also be shown that the limit of the snow-covered part of SMIS can reach further north on Landsat images and varies seasonally. The northern radar limit of the smooth band would then outline the transition between marine ice and meteoric ice. We estimate the thickness of the snow deposit within the smooth band by using a simple three-layer model to quantify the reflectivity losses due to destructive interference from a thin film of snow over ice (Mouginot and others, 2009). We set the snow layer density to $600-\mathrm{kg} \cdot \mathrm{m}^{-3}$ to equal the average density measured south of the narrow smooth band. We find that for a thickness $<0.5 \mathrm{~m}$ at the time of acquisition, the snow layer would not produce noticeable coherent losses (less than $3 \mathrm{~dB}$ ) as observed.

\section{BASAL PROPERTIES}

The derived basal reflectance and backscattering coefficients, corrected for the measured surface transmission losses and hypothesized homogeneous englacial attenuation as described in Section 3.3, are shown in Fig. 4. As stated in Section 3.4, the basal reflectance and backscatter cannot be unambiguously inverted in terms of basal properties, especially since scattering from roughness and volumic structures might have an equally-dominant incoherent signature. To introduce and support the interpretation of the measured basal coefficients, we propose in the following section a means to provide insights into the physical interpretation of the radar signature in the specific setting of the ice-ocean interface.

\subsection{Interpretation insights}

Coherent response. Most ice shelves experience a combination of basal ice melting and (re)freezing at the ice-ocean interface (Rignot and others, 2013a). These processes create structures with different properties that affect the radar signal. A basal reflector that exhibits a strong reflectance together with a high coherent content, for instance, is indicative of a very flat surface with little heterogeneous structures, suggesting an interface smoothed by homogeneous ice melting. Conversely, basal ice accretion usually generates a layer of marine ice with dielectric conductivities that could be more than one order of magnitude higher than that of meteoric ice (Tison and others, 1993), potentially modulating the radar reflectance response to some extent (Pettinelli and others, 2015). The recent detection of iron oxide in a marine ice core from Amery Ice Shelf, Antarctica, might be an explanation for such high conductivity (Herraiz-Borreguero and others, 2016). The reflectance may also be sensitive to the marine ice layer if its thickness is less than the radar vertical resolution ( $\sim 6 \mathrm{~m}$ in ice). In this case, the ice-ocean interface can be approximated as a thin film stack whose effective reflectance properties are mainly modulated by the marine ice thickness because of signal interferences between the top and bottom reflections of the accreted layer. The conjugated effects of destructive interferences and marine ice attenuation would tend to fade the signal with marine ice thickness increase (Yeh, 1998).

Incoherent response. The structure of accreted ice is expected to be significantly heterogeneous between the Fraunhofer and Rayleigh scales $(\lambda / 32=0.15 \mathrm{~m}$ and $\lambda / 8=$ $0.62 \mathrm{~m}$, respectively), where radar scattering is boosted and eventually dominates the signal (Ulaby and others, 1981). The formation of accreted marine ice is a bottom-up process starting with the nucleation of suspended frazil ice crystals in supercooled water (Martin, 1981; Daly, 1984), eventually growing, coalescing, and accumulating at the ice-shelf bottom. Consequently, the first bottom layer of marine ice is usually permeable, and then compacts upward, leading to a medium rich in inclusions such as trapped sea water, along with lithogenic and biogenic 


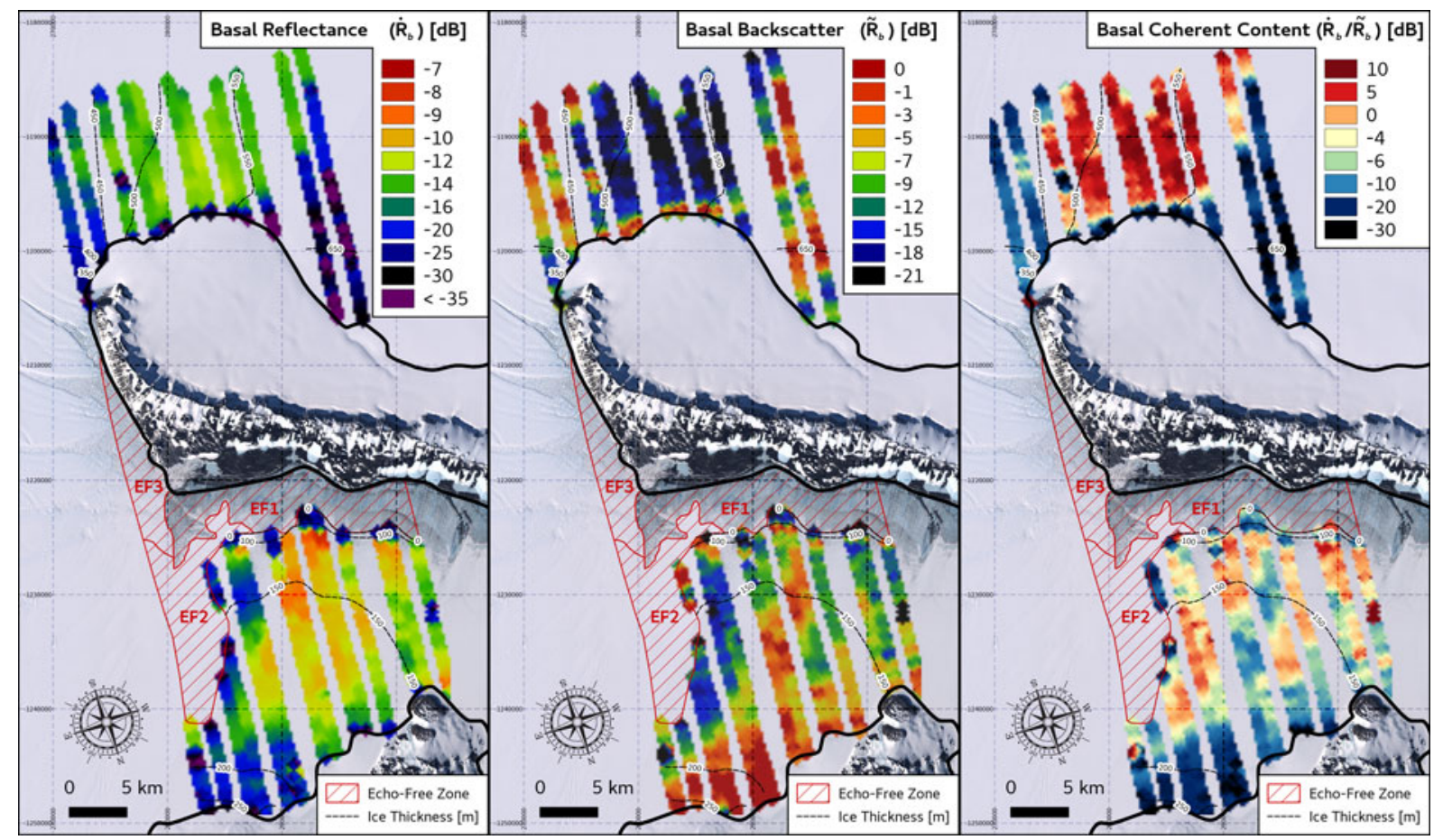

Fig. 4. (Left) Basal reflectance, which is mainly dependent on basal permittivity gradient and deterministic structure (e.g., horizontal layering), unless the backscatter is very high. (Middle) Basal backscatter, which is mainly dependent on basal roughness and macroscopic volumic heterogeneities. (Right) The basal coherent content, which is independent of basal permittivity gradient and englacial attenuation, inversely patterns the strength of the geometric heterogeneities at the basal interface (i.e., a low coherent content corresponds to a strong geometric heterogeneities).

debris (Craven and others, 2005, 2009; Treverrow and others, 2010). In this highly compositionally and geometrically heterogeneous medium, the strength of the radar backscatter can be a proxy to the location of frazil/marine ice and possibly also to assess its relative growth maturity.

Ambiguities. Whilst there are few alternatives to ice-shelf basal melting for the formation of a strong and coherent basal reflector, the interpretation of an incoherent return can be ambiguous: a heterogenous basal structure at radar scale could result from cracks or short basal terraces. Basal terraces have been observed at the base of ice shelves associated with Darwin-Hatherton (East Antarctica)(Riger-Kusk, 2011), Pine Island (West Antarctica), and Petermann (Greenland) (Dutrieux and others, 2014) glaciers, as well as at northern SMIS (Ryan, 2016) together with basal crevasses (Rosier and others, 2017). On radargrams, such terraces usually appear as a series of periodic bent steps arranged perpendicular to an ice thickness gradient and separated by an abrupt near-vertical wall. Although their radar character is not incompatible with crevasses from mechanical origins, differential basal melting from ascending meltwater formed at the grounding line is usually favored as the driving process (Dutrieux and others, 2014).

\subsection{Basal reflectance and backscatter}

Basal reflectance and backscatter (Fig. 4) exhibit both meaningful and very specific patterns that we will attempt to classify and interpret in the following. The basal reflectance shows a distinct pattern, whereby the center of SMIS has higher values (between -12 and $-7 \mathrm{~dB}$ ) than around its edges in the northeast, east, and south. The basal backscatter is lowest in the northeast portion of SMIS and decreases gradually toward its center. A more abrupt change from around -1 to $-15 \mathrm{~dB}$ occurs between the northeast and the center-east of the ice-shelf, adjacent to the shear zone to RIS. The basal coherent content is lowest $(-30$ to $-10 \mathrm{~dB})$ in its north and varies between 6 and $5 \mathrm{~dB}$ in its center. Around its eastern and southern margins, the basal coherent content drops again to -20 to $10 \mathrm{~dB}$. Echo-free (EF) zones (e.g., without distinguishable reflector following the surface) are also identified within SMIS.

Remarkably, the reflectance and backscatter basal properties sharply change at specific depths over both RIS (at about 440 and $580 \mathrm{~m}$ ) and SMIS (at about 105 and $200 \mathrm{~m}$ ) as seen in Fig. 5a-b. Here, the ice thickness is related to the depth of the basal reflector below the surface not the absolute depth below sea-level, which needs hydrostatic correction. We hypothesize that these sharp backscatter gradients are isolines at which the pressure melting point is reached because they occur along specific depths and they delineate units dominated alternatively by scattering and reflectance, as expected by melting and freezing processes respectively. The temperature of the pressure melting point and its associated location along the ice-ocean interface of the ice-shelf base is mainly driven by local ocean salinity, the thermohaline circulation pattern, and the actual interface depth (e.g., Galton-Fenzi and others, 2012; Gwyther and others, 2018).

Here, we propose that a sharp gradient delimiting a highto-low $\dot{R}_{\mathrm{b}} / \tilde{R}_{\mathrm{b}}$ ratio is a boundary between a melting and freezing ice-ocean interface, respectively, as the latter should be characterized by a growing non-deterministic structure responsible for a stronger signal backscatter. Thus, this technique provides insights for determining the location of the pressure melting point at the ice-shelf base.

\subsection{Basal units}

The detected ice thickness depth isolines matching a sharp modification in the radar properties are used to outline six 


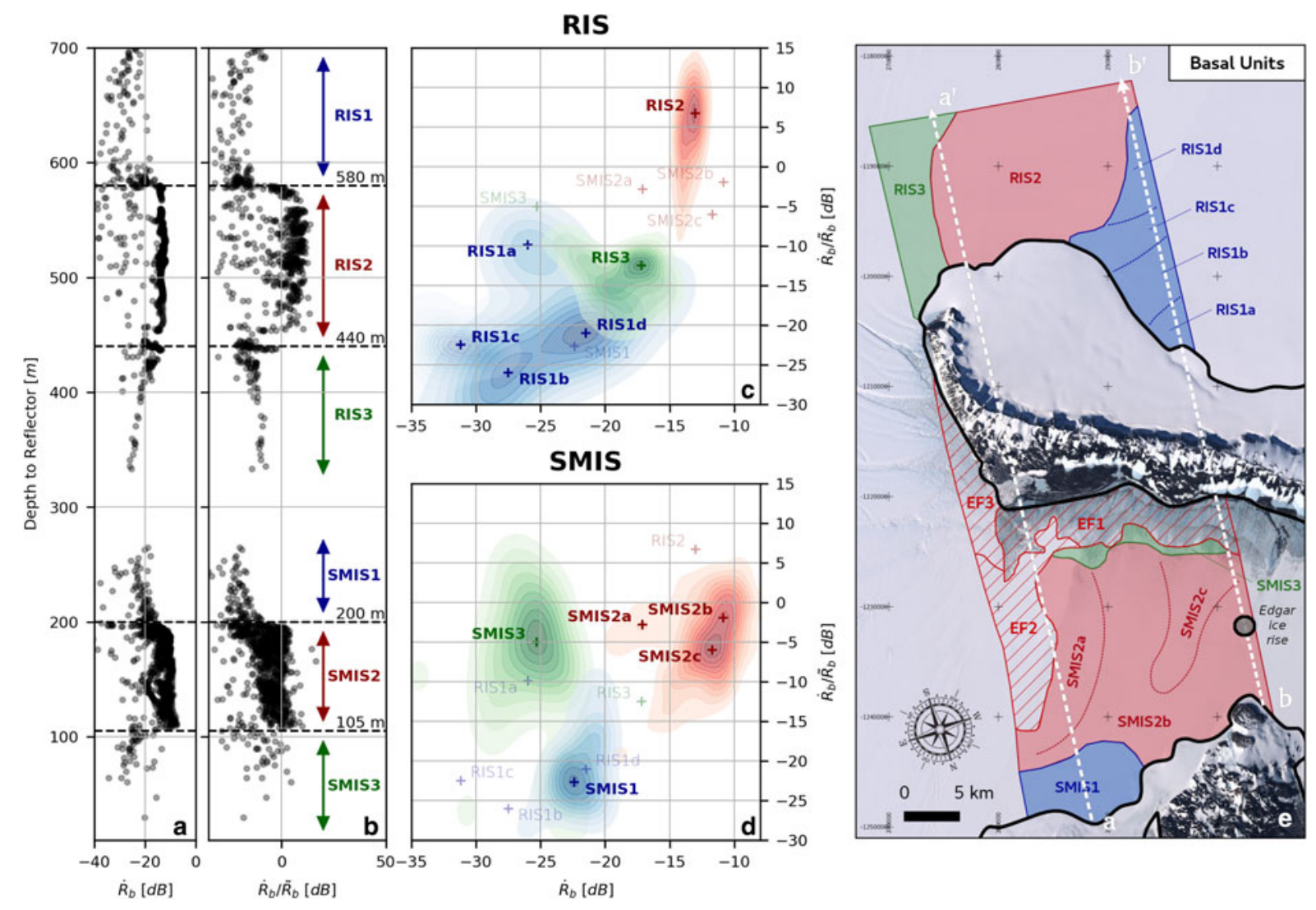

Fig. 5. Basal reflectance (a) and basal coherent content (b) as a function of depth to the related reflector for both RIS and SMIS. On a first approach, the behavior of these properties can be classified into various regimes sharply transitioning around specific depths (105, 200, 440, $580 \mathrm{~m}$ ), delimiting six main units (RIS1-3 and SMIS1-3). A kernel density estimation of the distribution of the same data set in the reflectance vs coherent content space is shown for RIS (c) and SMIS (d). It supports identifying various sub-units with the joint use of Figure 4. Interestingly, while the main units are delimited by various depths, sub-units are not. The identified basal units are located on (e), also showing the radargram groundtracks from Figure 6 (dotted white lines).

main units (RIS1-3 and SMIS1-3) whose specific radar signatures and interpretations are discussed below. Within some of these units, additional sub-units (RIS1a-b and SMIS2a-c) can be distinguished, but their boundaries do not obviously match depth isolines. These sub-units are also discussed in the following paragraphs. Additionally, echo-free zones (EF13) where no basal detection occurs are also discussed. The radar properties of all the described units are gathered in Figure 5. C-D in the form of a two-parameter space plot classifying the units in terms of their $\dot{R}_{\mathrm{b}}$ and $\dot{R}_{\mathrm{b}} / \tilde{R}_{\mathrm{b}}$ coefficients. The location of each unit is shown in Figure $5 \mathrm{e}$, and a pair of illustrating radargrams is given in Figure 6.

EF1-3. An echo-free (EF) zone defines a unit where no subsurface return is detected below the surface echo. We have divided the EF zones into three units for which satellite imagery helps define different hypotheses that explain the absence of basal reflection. Within EF1, Landsat imagery outlines a wide field of blue ice identified by in situ ice samples mostly as a marine ice outcrop (Kellogg and others, 1991; Koch and others, 2015). The absence of a basal reflector can be explained by signal attenuation within the thick and highly conductive marine ice column (Pettinelli and others, 2015). EF2 marks the boundary between RIS and SMIS perpendicular flows (Clifford, 2005; Koch, 2016). The Landsat imagery does not distinguish EF2 visually from the surrounding white surface snow, which characterizes most ice shelves. We hypothesize EF2 to be a prolongation of the EF1 thick marine ice, but blanketed by a snow layer as described in Section 4.3. For EF3, the satellite imagery shows numerous crevasses and disrupted ice as also detected with ground-based ice penetrating radar (Arcone and others, 2016), in line with an area of high stress rates. Marine ice is also likely present here (Arcone and others, 2016). In this configuration of a rough and disordered media, the absence of basal detection could be explained by strong signal scattering, complemented by attenuation from conductive marine ice pockets within fractures.

RIS1. This is the deepest detected unit (below $580 \mathrm{~m}$ ). Overall, RIS1 is characterized by the weakest radar reflectance and reflectance/backscatter ratio of our data set, suggesting an area dominated by heterogeneous structures below radar scales. However, four sub-units (RIS1a-d) corresponding to the basal morphology trend indicate subtle basal variations. RIS1a radar properties stand out from its counterparts and a specific basal process cannot be ruled out here. Its stronger coherent content is indicative of a flatter interface. However, RIS1a's low reflectance is somewhat similar to that of RIS1b-d. This combination could be explained by localized basal melting where englacial attenuation has been overestimated (Matsuoka and others, 2012), thus lowering the perceived reflectance; or by the presence of a thin basal marine ice layer that would weaken the signal return by destructive interference. A melting hypothesis appears more likely in the usual scheme of cavity circulation where melting occurs at the deepest layer, close to the grounding line, and water becomes supercooled as it rises into thinner 

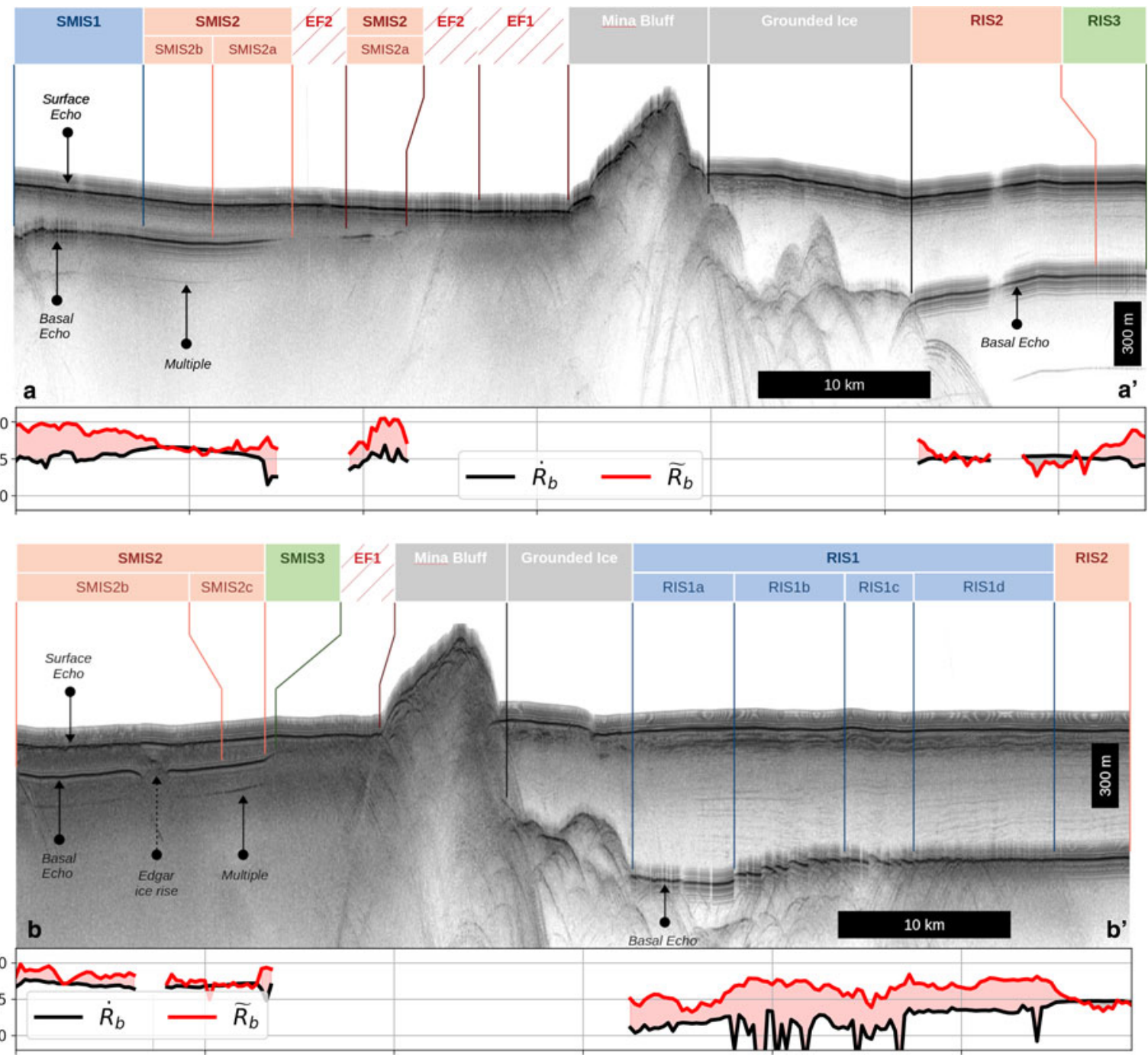

Fig. 6. HiCARS2 radargrams across the studied region, corresponding to the ground tracks shown in Fig. 5e. The primed letters of the crosssection naming are southward. The extent of the derived basal units are also highlighted. The horizontal and vertical scales are indicative only; they might vary slightly locally due to differential aircraft speed and surface range along each track. Below each radargram is plotted with the same identical horizontal scale the bed reflectance (black) and backscatter (red). The amplitude difference (color-filled area) between the two curves is indicative of the coherent content.

areas (Lewis and Perkin, 1986). Note that the hyperbolas around RIS1a's northern-half suggest proximity to the bedrock and grounding/floating transition.

The morphological character of RISb-d (Fig. 6b-b') is consistent with a basal-step setting with terraces up to 1-km long within RIS1b, where the base is the steepest. The terraces appear shorter in RISc and eventually fall below radar resolution in RIS1d where the base flattens but scattering hyperbolas from corner reflectors are still visible. This suggests that the basal step dimensions and formation processes are scaled by the basal slope. There are few and faint englacial layers distinguishable above RIS1b-c. Their apparently disturbed morphology suggests a foliation that could come from compression of the buttressed ice-shelf, locally thickening the ice and leading to a basal slope where the process responsible for the basal steps could initiate. However, a better resolved radar investigation might be necessary in this area to confirm the layer morphology. The englacial layers above RISd appear to bend downward, eventually intersecting the ice/ocean interface, and supporting a negative basal mass balance sustained by melting. However, the weak RISb-d radiometric properties are typical of what could be expected from ice accretion. A possibility for these sub-units is to have melting further north, closer to the grounding line, with subsequent melt water migration to shallower depths.

RIS2. This unit has the strongest reflectance/backscatter ratio $(+6.3 \mathrm{~dB})$ and one of the highest reflectances of the defined units. Both measurements together are a strong signature of what could be expected from a wide and flat field of basal melting. The relatively steady reflectance across the unit supports the hypothesis of a highly deterministic interface. Note that a narrow $1-\mathrm{km}$ band of low reflectance (visible on Fig. 4) is present along the coast line in the vicinity of the grounded Minna Bluff Glacier. This band might be attributed to the grounding/floating ice transition with the presence of bedrock scattering.

RIS3. The radar properties of the basal reflectors get notably weaker from RIS2 to RIS3. The alternation of melting/freezing processes at ice-shelf's base suggests that RIS3 might be a region of ice accretion that follows the suggested melting in RIS2. The thinner RIS would allow traveling of ice-shelf water to these shallower heights and an associated loss of overburden pressure allowing for supercooling 
of the water mass and thus frazil ice formation. The possibility of scattering from a basal-step setting similar to RIS1 is unlikely since such a basal character does not appear on the radargram in Figure 6a-a'. In particular, the base at RIS3 is continuous and does not exhibit any scattering hyperbolas that seem to accompany basal steps at RIS1.

SMIS1. A basal-step setting has been previously detected at SMIS1 with a higher-frequency ground radar (Ryan and Christensen, 2012). The steps are too small to be well resolved by HiCARS2, but the existing ice thickness gradient (Fig. 6a-a'), together with the weak radiometric properties quasi-similar to RIS1d, suggest that SMIS1 is amenable to basal step formation. Note that sub-unit identification within SMIS1 is not as obvious as compared to RIS1. This is probably due to its smaller extent, at the threshold of the RSR technique horizontal resolution.

SMIS2. This unit has complex radar properties. The basal reflectance does not exhibit sharp gradients and has an overall strength more similar to inferred melting ice (e.g., RIS2) than freezing ice (e.g., RIS3). A steady southward increase of the reflectance suggests a progressive modification of the deterministic composition/structure of the ice-ocean interface. As discussed in Section 5.1, such an effect could be caused by an increasing permittivity gradient and/or the presence of a $<6 \mathrm{~m}$ marine ice layer thinning toward Minna Bluff.

SMIS2a is a sub-unit bordering EF2 over a 3-km wide band where both the basal reflectance and scattering are weak. We propose SMIS2a to be a transition unit where the marine ice content within the vertical ice column is rapidly decreasing westward from EF2. The marine ice is likely generated as the ice-shelf water 'climbs' from the RIS cavity into the much thinner SMIS cavity (Koch and others, 2015).

The rest of SMIS2 has a coherent content behavior that differs from the reflectance map. We distinguish two additional sub-units with specific reflectance and backscatter properties, SMIS2b-c, as 3-km wide bands somewhat perpendicular to the thickness gradient, but parallel to iceshelf flow (Clifford, 2005; Koch, 2016). Together, EF2 and the bands formed by SMIS2a-c appear to be more-or-less arranged radially from SMIS1. We propose three hypotheses to account for this setting:

(1) As for RIS1, thermohaline circulation gradients could be responsible for an active east-west differential marine ice growth/decay across the unit, or possibly non-mature frazil ice. However, such an ice accretion trend, which is not correlated with the ice thickness gradient, is hard to reconcile with the observed perpendicular reflectance variation that we postulated for a progressive evolution in maturity of accreted marine ice content.

(2) In contrast to active accretion at present day, SMIS2b-c could be relics of former differential basal mass balances upstream of the ice-shelf flow, possibly originating from the EF2 location. The SMIS flow velocity does not exceed $6 \mathrm{~m} \cdot \mathrm{a}^{-1}$ at its heart according to GPS measurements (Clifford, 2005). Given that the bands formed by SMISb-c are up to $\sim 4 \mathrm{~km}$ wide, and assuming a constant ice-shelf velocity over time, it would indicate a basal mass balance variability over a 700 year timescale. However, this hypothesis would require a recent and drastic change in the basal accumulation rate given that today's echo-free zone EF2 suggests much thicker marine ice than the thin layer variability that was hypothesized for SMIS2a, unless SMIS2b-c is melting and eroding the marine ice thickness previously accreted upflow.

(3) SMIS2a might be a marine ice accretion prism in the continuity of EF2, similar to, but not as abrupt as, SMIS3 and EF1, respectively. Then, SMIS2c could simply be explained by a different ocean circulation regime influenced locally by the Edgar Ice Rise located in centerwest SMIS (see Fig. 5e), which is a vertical bedrock intrusion locally grounding the ice and on which the ice-shelf is buttressing (Clifford, 2005; Rack and others, 2017; Wild and others, 2018). This pinning point can be easily identified on the HiCARS2 radargrams (Fig. 6b-b').

SMIS3. This unit is a narrow feature between EF1 and SMIS2 geometrically characterized by a sudden decrease in the ice thickness (Fig. 4) and associated steep basal reflectors, in contrast to the gentle slope of SMIS2 (Fig. 6b-b'). Although its weak reflectance is similar to RIS1, its strong coherent content is a signature of a deterministic flat interface. Bundled together, these properties likely indicate a meteoric/ marine interface for which the dielectric gradient is known to be far lower than for an ice-ocean interface (Pettinelli and others, 2015). This argument is supported by the known exposure of marine ice at the ice-shelf surface within the adjacent EF1. Such a setting accommodates the ice-shelf vertical structure proposed by Koch (2016) from ground radar observations. In that scenario, the slope break in the basal reflector delimiting SMIS2 from SMIS3 (Fig. 6) would indicate the location where the thickness of accumulated marine ice exceeds the radar vertical resolution. The marine ice column would then grow southward until surface exposure.

\section{CONCLUSIONS AND PROSPECTS}

Ice shelves are crucial regulators of the grounded ice flow into the ocean for two-thirds of the Antarctic ice sheet through buttressing at passive margins and local pinning points (Bindschadler and others, 2011). Ice-shelf disruption accelerates the transfer of land ice into the ocean that will eventually melt and contribute to sea level rise (De Angelis and Skvarca, 2003; Scambos and others, 2004). The assessment of ice-shelf stability requires a knowledge of the boundary conditions at both their surface and basal (i.e., ice-ocean) boundaries (Gwyther and others, 2015). Firn density, ice composition, and geometric structure (e.g., roughness) are all properties scaled by the processes contributing to the ice shelves mass balance at these boundaries, making them important observables to assess ice-shelf stability. However, global climate models and continental data sets rendering the surface properties do not account for the local singularities that might better explain the behavior of a regional catchment (e.g., Grima and others, 2014a; Cook and others, 2018). Likewise, constraining basal boundary conditions in situ is logistically challenging, while access through ice coring provides only a sparse sampling of an entire iceshelf (Oerter and others, 1992; Tison and others, 1993; Treverrow and others, 2010), although core site locations can be supported by ground penetrating radar with limited range deployment.

Our analysis focused on SMIS and a portion of the RIS. SMIS is separated from RIS by a rift zone and exhibits a heterogeneous ice composition made of both marine and meteoric ice (Kellogg and others, 1991; Fitzsimons and others, 2012b; 
Koch and others, 2015), suggesting a complex mass balance where both surface and basal processes compete equally. We used ice penetrating radar data obtained in a 2014-15 austral summer airborne survey and developed a methodology to extend the application of the RSR technique from the surface to the basal radio properties at a scale relevant to detect local singularities that might play a critical role in iceshelf mass balance.

The surface radar properties are inverted in terms of surface snow density and root-mean-square heights, leading to a distribution pattern of the processes contributing to the surface boundary conditions that are compatible with the observed marine ice exposure along Minna Bluff. We locate the transition between the marine ice exposure and the meteoric ice, below a thin $<0.5 \mathrm{~m}$ layer of fresh snow at the time of survey.

The ratio of the RSR-derived basal reflectance and backscatter coefficients provides the basal coherent content, a measurement of the geometric disorder at the ice-ocean boundary that is corrected for both surface transmission losses and englacial attenuation. The basal radar properties exhibit sharp and strong gradients along specific iso-depths, suggesting an abrupt modification of the ice composition and geometric structure at the ice-ocean boundary. We argue that this behavior demonstrates RSR identification of locations where the pressure-melting point is reached. Our framework for classifying basal radiometric properties further sheds light on basal boundary condition patterns and their related processes, driven mainly by the freezing and melting of ice. For example, basal steps are observed at both SMIS and RIS, suggesting a common geometric expression of some basal processes hypothesized to be driven by ascending meltwater formed at the grounding line (Dutrieux and others, 2014).

Future directions include addressing ambiguities that remain for interpretation of the basal radio properties. This could be achieved by, first, better understanding of the spectra of dielectric properties and geometric structures offered by frazil ice and refrozen marine ice with brine inclusions, and second, by further quantifying the interactions of radio waves with these media.

Terrestrial ice-shelf cavities also provide a unique and accessible analog for ice-covered ocean worlds in the solar system. For example, the salinity and pressure at the basal boundaries of terrestrial ice shelves is comparable to what is expected at Europa (Blankenship and others, 2009), the Jovian icy moon that may harbor conditions suitable for life (Reynolds and others, 1983). As for Earth, the accretion of frozen marine ice at the ice/ocean interface of Europa can act as a mechanism for trapping ocean material (Craven and others, 2005; Howell and Pappalardo, 2018), including possible relics of an active habitat, while its distribution is an indicator of ocean circulation (Soderlund and others, 2013).

Europa is the target of NASA's upcoming Europa Clipper mission (Phillips and Pappalardo, 2014) to be launched in the early 2020s to investigate the satellite's habitability. The Radar for Europa Assessment and Sounding: Ocean to Nearsurface (REASON) instrument, a multi-frequency, multichannel ice penetrating radar system with a VHF band that is similar in frequency and bandwidth to HiCARS2, could revolutionize our understanding of Europa's ice shell by providing the first direct measurements of its surface character and subsurface structure. The techniques developed here will provide an exciting new data analysis approach for characterizing the surface and basal boundary conditions along the ice-ocean interface as well as any liquid water lenses embedded within the ice shell (Schmidt and others, 2011).

\section{ACKNOWLEDGMENTS}

This work was supported by the G. Unger Vetlesen Foundation. CG and DMS were supported, in part, by grant \#NNX16AJ95G from the NASA Cryospheric Sciences Program. IK was supported by ICIMOD's Cryosphere Initiative funded by Norway, and by core funds of ICIMOD contributed by the governments of Afghanistan, Australia, Austria, Bangladesh, Bhutan, China, India, Myanmar, Nepal, Norway, Pakistan, Sweden, and Switzerland. We are very grateful for a SCAR/COMNAP Fellowship that sponsored a research stay of IK at UTIG. We acknowledge the Norwegian Polar Institute's Quantarctica package. This is UTIG contribution \#3458.

\section{REFERENCES}

Akkermans E, Wolf PE and Maynard R (1986) Coherent backscattering of light by disordered media: analysis of the peak line shape. Phys. Rev. Lett., 56(14), 1471-1474 (doi: 10.1103/ PhysRevLett.56.1471)

Alley KE, Scambos TA, Siegfried MR and Fricker HA (2016) Impacts of warm water on Antarctic ice shelf stability through basal channel formation. Nat. Geosci., 9, 290-293 (doi: 10.1038/ngeo2675)

Arcone SA and 5 others (2016) Ground-penetrating radar profiles of the Mcmurdo shear zone, Antarctica, acquired with an unmanned rover: interpretation of crevasses, fractures, and folds within firn and marine ice. Geophysics, 81(1), WA21WA34 (doi: 10.1190/geo2015-0132.1)

Banwell AF and Macayeal DR (2015) Ice-shelf fracture due to viscoelastic flexure stress induced by fill/drain cycles of supraglacial lakes. Antarct. Sci., 27, 587-597 (doi: 10.1017/ S0954102015000292)

Berger S, Favier L, Drews R, Derwael JJ and Pattyn F (2016) The control of an uncharted pinning point on the flow of an Antarctic ice shelf. J. Glaciol., 62, 37-45 (doi: 10.1017/ jog.2016.7)

Bevan SL and 9 others (2017) Centuries of intense surface melt on Larsen C ice shelf. Cryosphere, 11, 2743-2753 (doi: 10.5194/ tc-11-2743-2017)

Bindschadler R and 8 others (2008) The landsat image mosaic of Antarctica. Rem. Sens. Environ., 112, 4214-4226.

Bindschadler R and 17 others (2011) Getting around Antarctica: new high-resolution mappings of the grounded and freely-floating boundaries of the Antarctic ice sheet created for the international polar year. Cryosphere, 5, 569-588 (doi: 10.5194/tc-5-569-2011)

Blankenship DD, Young DY, Moore WB and Moore JC (2009) Radar sounding of Europa's subsurface properties and processes: the view from Earth, 631-653. The University of Arizona Press, Tucson.

Clifford AE (2005) The physiography, flow characteristics and vulnerability of the Southern McMurdo Ice Shelf, Antarctica. Ph.D. thesis, University of Otago, New Zealand.

Cook S, Galton-Fenzi BK, Ligtenberg SRM and Coleman R (2018) Brief communication: widespread potential for seawater infiltration on Antarctic ice shelves. Cryosphere Discussions, 12, 38533859 (doi: 10.5194/tc-2018-146)

Cook AJ and Vaughan DG (2010) Overview of areal changes of the ice shelves on the Antarctic Peninsula over the past 50 years. Cryosphere, 4(1), 77-98 (doi: 10.5194/tc-4-77-2010)

Craven $M$ and 7 others (2005) Borehole imagery of meteoric and marine ice layers in the amery ice shelf, East Antarctica. J. Glaciol., 51(172), 75-84 (doi: 10.3189/172756505781829511) 
Craven M, Allison I, Fricker HA and Warner R (2009) Properties of a marine ice layer under the amery ice shelf, East Antarctica. J. Glaciol., 55, 717-728 (doi: 10.3189/002214309789470941)

Daly SF (1984) Frazil ice dynamics. Cold Regions Research and Engineering Lab Hanover $\mathrm{NH}$.

De Angelis H and Skvarca P (2003) Glacier surge after ice shelf collapse. Science, 299(5579), 1560-1563 (doi: 10.1126/ science.1077987)

Depoorter MA and 6 others (2013) Calving fluxes and basal melt rates of Antarctic ice shelves. Nature, 502(7469), 89-92 (doi: 10.1038/nature12567)

De Rydt J, Hilmar Gudmundsson G, Nagler T, Wuite J and King EC (2018) Recent rift formation and impact on the structural integrity of the brunt ice shelf, East Antarctica. Cryosphere, 12, 505-520 (doi: 10.5194/tc-12-505-2018)

Destrempes F and Cloutier G (2010) A critical review and uniformized representation of statistical distributions modeling the ultrasound echo envelope. Ultrasound. Med. Biol., 36(7), 1037-51 (doi: 10.1016/j.ultrasmedbio.2010.04.001)

Dierckx M and Tison JL (2013) Marine ice deformation experiments: an empirical validation of creep parameters. Geophys. Res. Lett., 40, 134-138 (doi: 10.1029/2012GL054197)

Dinniman MS, Klinck JM and Smith WO (2007) Influence of sea ice cover and icebergs on circulation and water mass formation in a numerical circulation model of the Ross sea, Antarctica. J. Geophys. Res. Oceans., 112, C11013 (doi: 10.1029/2006JC004036)

Dow CF and 8 others (2018) Basal channels drive active surface hydrology and transverse ice shelf fracture. Sci. $A d v ., 4(6)$, eaao7212 (doi: 10.1126/sciadv.aao7212)

Dupont TK and Alley RB (2005) Assessment of the importance of ice-shelf buttressing to ice-sheet flow. Geophys. Res. Lett., 32, L04503 (doi: 10.1029/2004GL022024)

Dutrieux P and 6 others (2014) Basal terraces on melting ice shelves. Geophys. Res. Lett., 41, 5506-5513 (doi: 10.1002/ 2014GL060618)

Fitzsimons S, Mager S, Frew R, Clifford A and Wilson G (2012a) Formation of ice-shelf moraines by accretion of sea water and marine sediment at the southern margin of the Mcmurdo ice shelf, Antarctica. Ann. Glaciol., 53(60), 211-220 (doi: 10.3189/ 2012AoG60A155)

Fitzsimons S, Mager S, Frew R, Clifford A and Wilson G (2012b) Formation of ice-shelf moraines by accretion of sea water and marine sediment at the southern margin of the Mcmurdo ice shelf, Antarctica. Ann. Glaciol., 53, 211-220 (doi: 10.3189/ 2012AoG60A155)

Fricker HA, Popov S, Allison I and Young N (2001) Distribution of marine ice beneath the amery ice shelf. Geophys. Res. Lett., 28(11), 2241-2244 (doi: 10.1029/2000GL012461)

Fürst JJ and 6 others (2016) The safety band of Antarctic ice shelves. Nat. Clim. Chang., 6, 479-482 (doi: 10.1038/nclimate2912)

Galton-Fenzi BK, Hunter JR, Coleman R, Marsland SJ and Warner RC (2012) Modeling the basal melting and marine ice accretion of the amery ice shelf. J. Geophys. Res., 117, C09031 (doi: 10.1029/2012JC008214)

Grima C and 6 others (2016) Radar detection of the brine extent at mcmurdo ice shelf, Antarctica, and its control by snow accumulation. Geophys. Res. Lett., 43(13), 7011-7018 (doi: 10.1002/ 2016GL069524)

Grima C and 7 others (2017) Surface roughness of titan's hydrocarbon seas. Earth. Planet. Sci. Lett., 474, 20-24 (doi: 10.1016/j. epsl.2017.06.007)

Grima C, Blankenship DD, Young DA and Schroeder DM (2014a) Surface slope control on firn density at thwaites glacier, West Antarctica: results from airborne radar sounding. Geophys. Res. Lett., 41(19), 6787-6794 (doi: 10.1002/2014GL061635)

Grima C, Kofman W, Herique A, Orosei R and Seu R (2012) Quantitative analysis of mars surface radar reflectivity at 20 MHz. Icarus, 220, 84 (doi: 10.1016/j.icarus.2012.04.017)

Grima C, Schroeder DM, Blankenship DD and Young DA (2014b) Planetary landing-zone reconnaissance using ice-penetrating radar data: concept validation in Antarctica. Planet. Space. Sci., 103, 191-204 (doi: 10.1016/j.pss.2014.07.018)

Gudmundsson GH (2013) Ice-shelf buttressing and the stability of marine ice sheets. Cryosphere, 7, 647-655 (doi: 10.5194/tc-7-6472013)

Gwyther DE, Galton-Fenzi BK, Dinniman MS, Roberts JL and Hunter JR (2015) The effect of basal friction on melting and freezing in ice shelf-ocean models. Ocean Modelling, 95, 38-52 (doi: 10.1016/j.ocemod.2015.09.004)

Gwyther DE, O'Kane TJ, Galton-Fenzi BK, Monselesan DP and Greenbaum JS (2018) Intrinsic processes drive variability in basal melting of the totten glacier ice shelf. Nat. Commun., 9 (1) (doi: 10.1038/s41467-018-05618-2)

Herraiz-Borreguero L, Lannuzel D, van der Merwe P, Treverrow A and Pedro JB (2016) Large flux of iron from the amery ice shelf marine ice to prydz bay, East Antarctica. J. Geophys. Res. Oceans., 121, 6009-6020 (doi: 10.1002/2016JC011687)

Howell SM and Pappalardo RT (2018) Band formation and oceansurface interaction on Europa and Ganymede. Geophys. Res. Lett., 45, 4701-4709 (doi: 10.1029/2018GL077594)

Hubbard B and 12 others (2016) Massive subsurface ice formed by refreezing of ice-shelf melt ponds. Nat. Commun., 7, 11897 (doi: 10.1038/ncomms11897)

Jakeman $\mathrm{E}$ (1980) On the statistics of $k$-distributed noise. J. Phys. A: Math. General, 13(1), 31-48 (doi: 10.1088/0305-4470/13/1/006)

Jakeman E and Tough RJA (1987) Generalized $k$ distribution: a statistical model for weak scattering. J. Optical Soc. Am. A, 4(9), 1764 (doi: 10.1364/JOSAA.4.001764)

Jansen D and 6 others (2015) Brief communication: newly developing rift in Larsen $\mathrm{C}$ ice shelf presents significant risk to stability. Cryosphere, 9, 1223-1227 (doi: 10.5194/tc-9-1223-2015)

Jansen D, Luckman A, Kulessa B, Holland PR and King EC (2013) Marine ice formation in a suture zone on the Larsen $C$ ice shelf and its influence on ice shelf dynamics. J. Geophys. Res. Earth. Surf., 118, 1628-1640 (doi: 10.1002/jgrf.20120)

Kaspers KA and 5 others (2004) Model calculations of the age of firn air across the Antarctic continent. Atmos. Chem. Phys., 4(5), 1365-1380 (doi: 10.5194/acp-4-1365-2004)

Kellogg TB, Kellogg DE and Stuiver M (1991) Oxygen isotope data from the mcmurdo ice shelf, Antarctica: implications for debris band formation and glacial history. Antarct. J. US, 26(5), 73-76.

Kendrick AK and 12 others (2018) Surface meltwater impounded by seasonal englacial storage in west greenland. Geophys. Res. Lett., 45(19), 10,474-10,481 (doi: 10.1029/2018GL079787)

King EC, De Rydt J and Hilmar Gudmundsson G (2018) The internal structure of the brunt ice shelf from ice-penetrating radar analysis and implications for ice shelf fracture. Cryosphere, 12, 33613372 (doi: 10.5194/tc-12-3361-2018)

Koch I (2016) Marine ice formation and deformation at the Southern McMurdo Ice Shelf. Ph.D. thesis, University of Otago, Dunedin, New Zealand.

Koch I, Fitzsimons S, Samyn D and Tison JL (2015) Marine ice recycling at the southern mcmurdo ice shelf, Antarctica. J. Glaciol., 61, 689-701 (doi: 10.3189/2015JoG14J095)

Kovacs A, Gow AJ and Morey RM (1995) The in-situ dielectric constant of polar firn revisited. Cold. Reg. Sci. Technol., 23(3), 245-256 (doi: 10.1016/0165-232X(94)00016-Q)

Kuipers Munneke P and 15 others (2017) Observationally constrained surface mass balance of Larsen C ice shelf, Antarctica. Cryosphere, 11, 2411-2426 (doi: 10.5194/tc-11-2411-2017)

Lewis EL and Perkin RG (1986) Ice pumps and their rates. J. Geophys. Res., 91(C10), 11756 (doi: 10.1029/JC091 iC10p11756)

Ligtenberg SRM, Helsen MM, van den Broeke MR (2011) An improved semi-empirical model for the densification of Antarctic firn. Cryosphere, 5, 809 (doi: 10.5194/tc-5-809-2011)

Liu Y and 7 others (2015) Ocean-driven thinning enhances iceberg calving and retreat of Antarctic ice shelves. Proc. Natl. Acad. Sci. USA, 112(11), 3263-8 (doi: 10.1073/pnas.1415137112)

Martin S (1981) Frazil ice in rivers and oceans. Annu. Rev. Fluid. Mech., 13(1), 379-397 (doi: 10.1146/annurev.fl.13.010181.002115) 
Matsuoka K and 19 others (2015) Antarctic ice rises and rumples: their properties and significance for ice-sheet dynamics and evolution. Earth-Sci. Rev., 150, 724-745 (doi: 10.1016/j. earscirev.2015.09.004)

Matsuoka K, MacGregor JA and Pattyn F (2012) Predicting radar attenuation within the Antarctic ice sheet. Earth. Planet. Sci. Lett., 359, 173-183 (doi: 10.1016/j.epsl.2012.10.018)

McGrath D and 6 others (2014) The structure and effect of suture zones in the Larsen C ice shelf, Antarctica. J. Geophys. Res. Earth. Surf., 119, 588-602 (doi: 10.1002/2013JF002935)

Medley B and 12 others (2013) Airborne-radar and ice-core observations of annual snow accumulation over thwaites glacier, West Antarctica confirm the spatiotemporal variability of global and regional atmospheric models. Geophys. Res. Lett., 40, 36493654 (doi: 10.1002/grl.50706)

Moholdt G, Padman L and Fricker HA (2014) Basal mass budget of ross and filchner-ronne ice shelves, Antarctica, derived from lagrangian analysis of ICESat altimetry. J. Geophys. Res. Earth. Surf., 119, 2361-2380 (doi: 10.1002/2014JF003171)

Mouginot J and 5 others (2009) MARSIS surface reflectivity of the south residual cap of mars. Icarus, 201, 454 (doi: 10.1016/j. icarus.2009.01.009)

Oerter $\mathrm{H}$ and 6 others (1992) Evidence for basal marine ice in the Filchner-Ronne ice shelf. Nature, 358(6385), 399-401 (doi: 10.1038/358399a0)

Peters ME (2005) Analysis techniques for coherent airborne radar sounding: application to West Antarctic ice streams. J. Geophys. Res., 110(B6), B06303 (doi: 10.1029/2004JB003222)

Pettinelli E (2015) Dielectric properties of jovian satellite ice analogs for subsurface radar exploration: a review. Rev. Geophys., 53(3), 593-641 (doi: 10.1002/2014RG000463)

Phillips CB and Pappalardo RT (2014) Europa clipper mission concept: exploring jupiter's ocean moon. Eos, 95, 165-167 (doi: 10.1002/2014EO200002)

Pritchard HD and 5 others (2012) Antarctic ice-sheet loss driven by basal melting of ice shelves. Nature, 484(7395), 502-505 (doi: 10.1038/nature10968)

Putzig NE and 6 others (2017) Radar-derived properties of the insight landing site in western Elysium Planitia on mars. Space. Sci. Rev., 211(1-4), 135-146 (doi: 10.1007/s11214-016-0322-8)

Rack W, King MA, Marsh OJ, Wild CT and Floricioiu D (2017) Analysis of ice shelf flexure and its inSAR representation in the grounding zone of the Southern Mcmurdo ice shelf. Cryosphere, 11, 2481-2490 (doi: 10.5194/tc-11-2481-2017)

Rack W and Rott H (2004) Pattern of retreat and disintegration of the Larsen B ice shelf, Antarctic Peninsula. Ann. Glaciol., 39, 505510 (doi: 10.3189/172756404781814005)

Reynolds RT, Squyres SW, Colburn DS and McKay CP (1983) On the habitability of Europa. Icarus, 56(2), 246-254 (doi: 10.1016/ 0019-1035(83)90037-4)

Riger-Kusk M (2011) Ice dynamics of the Darwin-Hatherton glacial system, Transantarctic Mountains, Antarctica. Ph.D. thesis, University of Canterbury.

Rignot E, Jacobs S, Mouginot J and Scheuchl B (2013a) Ice-shelf melting around Antarctica. Science, 341(6143), 266-70 (doi: 10.1126/science.1235798)

Rignot E, Mouginot J, Larsen CF, Gim Y and Kirchner D (2013b) Lowfrequency radar sounding of temperate ice masses in southern alaska. Geophys. Res. Lett., 40, 5399-5405 (doi: 10.1002/ 2013GL057452)

Rignot E, Mouginot J and Scheuchl B (2011) Ice flow of the Antarctic ice sheet. Science, 333(6048), 1427-30 (doi: 10.1126/science.1208336)

Rosier SHR and 5 others (2017) On the interpretation of ice-shelf flexure measurements. J. Glaciol., 63, 783-791 (doi: 10.1017/ jog.2017.44)
Rutishauser A and 6 others (2016) Characterizing near-surface firn using the scattered signal component of the glacier surface return from airborne radio-echo sounding. Geophys. Res. Lett., 43(24), 12,502-12,510 (doi: 10.1002/2016GL071230)

Ryan MR (2016) Characteristics of the Ross and Southern McMurdo ice shelves as revealed from ground-based radar surveys. Ph.D. thesis, University of Canterbury.

Ryan AJ and Christensen PR (2012) Coils and polygonal crust in the Athabasca valles region, mars, as evidence for a volcanic history. Science, 336(6080), 449-52 (doi: 10.1126/science.1219437)

Scambos T and 7 others (2009) Ice shelf disintegration by plate bending and hydro-fracture: satellite observations and model results of the 2008 wilkins ice shelf break-ups. Earth. Planet. Sci. Lett., 280, 51-60 (doi: 10.1016/j.epsl.2008.12.027)

Scambos TA, Bohlander JA, Shuman CA and Skvarca P (2004) Glacier acceleration and thinning after ice shelf collapse in the larsen b embayment, Antarctica. Geophys. Res. Lett., 31, L18402 (doi: 10.1029/2004GL020670)

Scambos T, Hulbe C and Fahnestock M (2003) Climate-induced Ice Shelf disintegration in the Antarctic Peninsula, 79-92. Antarctic Research Series, American Geophysical Union (doi: 10.1029/ AR079p0079)

Schmidt BE, Blankenship DD, Patterson GW and Schenk PM (2011) Active formation of 'chaos terrain' over shallow subsurface water on Europa. Nature, 479(7374), 502-5 (doi: 10.1038/nature10608)

Schroeder DM, Blankenship DD and Young DA (2013) Evidence for a water system transition beneath thwaites glacier, West Antarctica. Proc. Natl. Acad. Sci. USA, 110(30), 12225-8 (doi: 10.1073/pnas.1302828110)

Schroeder DM, Grima C and Blankenship DD (2015) Evidence for variable grounding-zone and shear-margin basal conditions across thwaites glacier, West Antarctica. GEOPHYSICS, 81(1), WA35-WA43 (doi: 10.1190/GEO2015-0122.1)

Schroeder DM, Seroussi H, Chuw W and Young DA (2016) Adaptively constraining radar attenuation and temperature across the Thwaites glacier catchment using bed echoes. J. Glaciol., 62(236), 1075-1108 (doi: 10.1017/jog.2016.100)

Soderlund KM, Schmidt BE, Wicht J and Blankenship DD (2013) Ocean-driven heating of Europa's icy shell at low latitudes. Nat. Geosci., 7(1), 16-19 (doi: 10.1038/NGEO2021)

Tison JL, Ronveaux D and Lorrain RD (1993) Low salinity frazil ice generation at the base of a small Antarctic ice shelf. Antarct. Sci., 5, 309 (doi: 10.1017/S0954102093000409)

Treverrow A, Warner RC, Budd WF and Craven M (2010) Meteoric and marine ice crystal orientation fabrics from the amery ice shelf, East Antarctica. J. Glaciol., 56, 877-890 (doi: 10.3189/ 002214310794457353)

Ulaby FT, Moore RK and Fung AK (1981) Microwave Remote Sensing: Active and Passive, volume 1-3. Addison-Wesley, Reading, Massachusetts, Advanced Book Program.

van den Broeke M, Smeets P and Ettema J (2009) Surface layer climate and turbulent exchange in the ablation zone of the west greenland ice sheet. Int. J. Climatol., 29, 2309-2323 (doi: 10.1002/joc.1815)

Vaughan DG and 8 others (2012) Subglacial melt channels and fracture in the floating part of pine island glacier, Antarctica. J. Geophys. Res. Earth. Surf., 117, F03012 (doi: 10.1029/2012JF002360)

Wild CT, Marsh OJ and Rack W (2018) Unravelling inSAR observed Antarctic ice-shelf flexure using 2-d elastic and viscoelastic modelling. Front. Earth. Sci., 6, 28 (doi: 10.3389/feart.2018.00028)

Yeh P (1998) Optical Waves in Layered Media. John Wiley \& Sons, Inc., Hoboken, New Jersey.

Zotikov IA, Zagorodnov VS and Raikovsky JV (1980) Core drilling through the ross ice shelf (Antarctica) confirmed basal freezing. Science (New York, NY), 207(4438), 1463-5 (doi: 10.1126/ science.207.4438.1463) 